\title{
The Incentive to Trade under Ambiguity Aversion
}

\author{
Udo Broll* \\ Technische Universität Dresden \\ Kit Pong Wong \\ University of Hong Kong
}

September 2015

\begin{abstract}
This paper examines the behavior of an exporting firm that sells in both the home country and a foreign country. The firm makes its optimal production and export decisions when facing ambiguous exchange rate risk. Ambiguity is modeled by a second-order probability distribution that captures the firm's uncertainty about which of the subjective beliefs govern the exchange rate risk. Ambiguity preferences are modeled by the (second-order) expectation of a concave transformation of the (first-order) expected utility of profit conditional on each plausible subjective distribution of the exchange rate risk. Within this framework, we derive necessary and sufficient conditions under which the ambiguity-averse firm optimally sells more in the home country and exports less to the foreign country in response either to the introduction of ambiguity or to greater ambiguity aversion when ambiguity prevails. We further show that ambiguity and ambiguity aversion have adverse effect on the firm's incentive to export to the foreign country.
\end{abstract}

JEL classification: D21; D81; F31

Keywords: Ambiguity; Ambiguity aversion; Exports; Production

\footnotetext{
${ }^{*}$ We would like to thank Bernd Kempa (the Associate Editor) and two anonymous referees for helpful comments and suggestions. Correspondence to: Udo Broll, Department of Business and Economics; School of International Studies (ZIS), Technische Universität Dresden, 01062 Dresden, Germany, e-mail: udo.broll@tudresden.de (U. Broll).
} 


\title{
The incentive to trade under ambiguity aversion
}

\begin{abstract}
This paper examines the behavior of an exporting firm that sells in both the home country and a foreign country. The firm makes its optimal production and export decisions when facing ambiguous exchange rate risk. Ambiguity is modeled by a second-order probability distribution that captures the firm's uncertainty about which of the subjective beliefs govern the exchange rate risk. Ambiguity preferences are modeled by the (second-order) expectation of a concave transformation of the (first-order) expected utility of profit conditional on each plausible subjective distribution of the exchange rate risk. Within this framework, we derive necessary and sufficient conditions under which the ambiguity-averse firm optimally sells more in the home country and exports less to the foreign country in response either to the introduction of ambiguity or to greater ambiguity aversion when ambiguity prevails. We further show that ambiguity and ambiguity aversion have adverse effect on the firm's incentive to export to the foreign country.
\end{abstract}

JEL classification: D21; D81; F31

Keywords: Ambiguity; Ambiguity aversion; Exports; Production

\section{Introduction}

The study of an exporting firm under exchange rate uncertainty has been the subject of considerable research in decision making under uncertainty (Katz and Paroush, 1979; Kawai and Zilcha, 1986; Broll and Zilcha, 1992; Viaene and Zilcha, 1998; Wong, 2007; to name just a few). The extant literature examines the production and export decisions of the exporting firm using the standard von Neumann-Morgenstern expected utility representation. Such a modeling approach rules out the possibility that the firm is unable to unambiguously assign a probability distribution that uniquely describes the exchange rate risk, which gives rise to ambiguity, or uncertainty in the sense of Knight (1921). 
Since the seminal work of Ellsberg, ambiguity has been alluded to the violation of the independence axiom, which is responsible for the decision criterion being linear in the outcome probabilities. There are ample experiments (Einhorn and Hogarth, 1986; Sarin and Weber, 1993; Chow and Sarin, 2001) and surveys (Viscusi and Chesson, 1999; Chesson and Viscusi, 2003) that document convincing evidence that individuals prefer gambles with known rather than unknown probabilities, implying that ambiguity aversion prevails.

The purpose of this paper is to incorporate ambiguity into the model of an exporting firm that sells in both the home country and a foreign country. Klibanoff, Marinacci and Mukerji (2005) have recently developed a powerful decision criterion known as "smooth ambiguity aversion" that is compatible with ambiguity averse preferences under uncertainty (hereafter referred to as the KMM model). The KMM model features the recursive structure that is far more tractable in comparison to other models of ambiguity such as the pioneering maxmin expected utility (or multiple-prior) model of Gilboa and Schmeidler (1989). Specifically, the KMM model represents ambiguity by a second-order probability distribution that captures the firm's uncertainty about which of the subjective beliefs govern the exchange rate risk. The KMM model then measures the firm's expected utility under ambiguity by taking the (second-order) expectation of a concave transformation of the (first-order) expected utility of profit conditional on each plausible subjective distribution of the exchange rate risk. This recursive structure creates a crisp separation between ambiguity and ambiguity aversion, i.e., between beliefs and tastes, which allows us to study these two attributes independently. Another nice feature of the KMM model is that we can apply the conventional techniques in the decision making under uncertainty in the context of ambiguity (Taboga, 2005; Gollier, 2011; Snow, 2010, 2011; Alary et al., 2013; Wong, 2015, 2016).

Within the KMM model, we derive necessary and sufficient conditions under which the ambiguity-averse exporting firm optimally sells more in the home country and exports less to the foreign country in response either to the introduction of ambiguity or to greater ambiguity aversion when ambiguity prevails. We show that these conditions hold when the firm's coefficient of relative risk aversion does not exceed unity and its subjective beliefs are 
ranked in the sense of first-order stochastic dominance. Barham et al. (2014) document that the average coefficient of relative risk aversion is 0.8 in their sample of Midwestern grain farmers in the U.S., which is in line with the magnitudes of relative risk aversion found in many developing countries (Cardenas and Carpenter, 2008). Since exporting to the foreign country exposes the firm to the exchange rate risk, the prevalence of ambiguity creates additional risk to the ambiguity-averse firm. Hence, the firm finds it less attractive to export to the foreign country in the presence than in the absence of ambiguity. This result extends to the case of greater ambiguity aversion. Ambiguity and ambiguity aversion as such have adverse effect on the firm's incentive to export to the foreign country.

The rest of this paper is organized as follows. Section 2 delineates the KMM model of an exporting firm that sells in both the home country and a foreign country. The firm faces ambiguous exchange rate uncertainty in the sense of Knight (1921). Section 3 derives the firm's optimal production and export decisions. Section 4 examines how ambiguity and ambiguity aversion affect the value of export to the foreign country. The final section concludes.

\section{The model}

Consider an exporting firm that faces exchange rate uncertainty. There is one period with two dates, 0 and 1 . To begin, the firm produces a single homogeneous good in the home country according to a known cost function, $C(Q)$, where $Q \geq 0$ is the level of output and $C(Q)$ is compounded to date 1. The firm's production technology exhibits decreasing returns to scale so that $C(0)=C^{\prime}(0)=0$, and $C^{\prime}(Q)>0$ and $C^{\prime \prime}(Q)>0$ for all $Q>0$.

At date 1 , the firm sells its entire output, $Q$, in the home country and a foreign country. The firm commits its allocation of output at date 0 such that $Q_{d}$ units of the good are sold in the home market and the remaining units, $Q_{f}=Q-Q_{d}$, are exported to the foreign market, where $0 \leq Q_{d} \leq Q$. The firm is a price taker in both the home and foreign markets. The 
selling price in the home market is $P_{d}$ per unit, where $P_{d}>0$ is denominated in the home currency. On the other hand, the selling price in the foreign market is $P_{f}$ per unit, where $P_{f}>0$ is denominated in the foreign currency. ${ }^{1}$ The firm's profit at date 1 , denominated in the home currency, is given by

$$
\tilde{\Pi}=P_{d} Q_{d}+\tilde{S} P_{f} Q_{f}-C\left(Q_{d}+Q_{f}\right)
$$

where $\tilde{S}$ is the random spot exchange rate at date 1 and is expressed in units of the home currency per unit of the foreign currency. ${ }^{2}$ The firm possesses a von Neumann-Morgenstern utility function, $U(\Pi)$, defined over its home currency profit at date 1 , $\Pi$, with $U^{\prime}(\Pi)>0$ and $U^{\prime \prime}(\Pi)<0$, indicating the presence of risk aversion.

The spot exchange rate, $\tilde{S}$, is distributed according to an objective cumulative distribution function $(\mathrm{CDF}), F^{\circ}(S)$, over support $[\underline{S}, \bar{S}]$, where $0 \leq \underline{S}<\bar{S} \leq \infty$. The firm faces ambiguity in that it is uncertain about the objective $\mathrm{CDF}, F^{\circ}(S)$. Succinctly, the firm has a continuum of priors, $\{F(S \mid \theta): \theta \in[\underline{\theta}, \bar{\theta}]\}$, where $F(S \mid \theta)$ denotes a plausible first-order CDF of $\tilde{S}$ over support $[\underline{S}, \bar{S}]$, which is sensitive to a parameter, $\theta$, whose value is not known ex ante. Based on its subjective information, the firm associates a second-order CDF, $G(\theta)$, over the continuum of priors, i.e., over support $[\underline{\theta}, \bar{\theta}]$, where $-\infty \leq \underline{\theta}<\bar{\theta} \leq \infty$. This captures the firm's uncertainty about which of the first-order CDF, $F(S \mid \theta)$, governs the random spot exchange rate, $\tilde{S}$. Following Gollier (2011), Snow (2010, 2011), and Wong (2015, 2016), we assume that the firm's ambiguous beliefs are unbiased in the sense that the expected exchange rate risk is equal to the objective exchange rate risk:

$$
\mathrm{E}_{G}[F(S \mid \tilde{\theta})]=F^{\circ}(S)
$$

for all $S \in[\underline{S}, \bar{S}]$, where $\mathrm{E}_{G}(\cdot)$ is the expectation operator with respect to the second-order $\mathrm{CDF}, G(\theta) .^{3}$

\footnotetext{
${ }^{1}$ Due to the segmentation of the home and foreign markets, arbitrage transactions are either impossible or unprofitable, thereby invalidating the law of one price. See Engel and Rogers $(1996,2001)$ and Parsley and Wei (1996) for supportive evidence that arbitrage transactions among national markets are indeed imperfect.

${ }^{2}$ Throughout the paper, random variables have a tilde $(\sim)$ while their realizations do not.

${ }^{3}$ The assumption that the expected exchange rate risk is equal to the objective exchange rate risk is
} 
The recursive structure of the KMM model implies that we can compute the firm's expected utility under ambiguity in three steps. First, we calculate the firm's expected utility for each first-order CDF of $\tilde{S}$. Second, we transform each (first-order) expected utility obtained in the first step by an ambiguity function, $\varphi(U)$, where $\varphi^{\prime}(U)>0$ and $U$ is the firm's utility level. Finally, we take the (second-order) expectation of the transformed expected utility obtained in the second step with respect to the second-order CDF of $\tilde{\theta}$. The firm's ex-ante decision problem as such is given by

$$
\max _{Q_{d} \geq 0, Q_{f} \geq 0} \mathrm{E}_{G}\left\{\varphi\left\{\mathrm{E}_{F}[U(\tilde{\Pi}) \mid \tilde{\theta}]\right\}\right\}
$$

where $\mathrm{E}_{F}(\cdot \mid \theta)$ is the expectation operator with respect to the first-order CDF, $F(S \mid \theta)$, and $\tilde{\Pi}$ is given by Eq. (1). Inspection of the objective function of program (3) reveals that the effect of ambiguity, represented by the CDF, $G(\theta)$, and the effect of ambiguity preferences, represented by the shape of $\varphi(U)$, can be separated and thus studied independently.

We say that the firm is ambiguity averse if, for any given pair of domestic sales and foreign exports, $\left(Q_{d}, Q_{f}\right)$, the objective function of program (3) decreases when the firm's ambiguous beliefs, specified by $G(\theta)$, change in a way that induces a mean-preserving spread in the distribution of the firm's expected utility. According to this definition, Klibanoff et al. (2005) show that ambiguity aversion implies concavity for $\varphi(U)$, and that a concave transformation of $\varphi(U)$ results in greater ambiguity aversion. To see this, we define the ambiguity aversion premium, $\Phi$, as the solution to the following equation:

$$
\mathrm{E}_{G}\left\{\varphi\left\{\mathrm{E}_{F}[U(\tilde{\Pi}) \mid \tilde{\theta}]\right\}\right\}=\varphi\left\{\mathrm{E}_{G}\left\{\mathrm{E}_{F}[U(\tilde{\Pi}) \mid \tilde{\theta}]\right\}-\Phi\right\}
$$

Hence, $\Phi$ measures the "pain" the firm is willing to suffer in order to get rid of the ambiguity. It follows from Eq. (4) and Jensen's inequality that $\Phi>0$ if, and only if, $\varphi^{\prime \prime}(U)<0$. To compare ambiguity aversion, we define $\Phi_{i}$ by

$$
\mathrm{E}_{G}\left\{\varphi_{i}\left\{\mathrm{E}_{F}[U(\tilde{\Pi}) \mid \tilde{\theta}]\right\}\right\}=\varphi_{i}\left\{\mathrm{E}_{G}\left\{\mathrm{E}_{F}[U(\tilde{\Pi}) \mid \tilde{\theta}]\right\}-\Phi_{i}\right\}
$$

motivated by the premise that the behavior of an ambiguity-neutral decision maker should be unaffected by the introduction of, or changes in, ambiguity. 
for $i=1$ and 2. It follows from Eq. (5) and Pratt (1964) that $\Phi_{1}<\Phi_{2}$ if, and only if, $-\varphi_{1}^{\prime \prime}(U) / \varphi_{1}^{\prime}(U)<-\varphi_{2}^{\prime \prime}(U) / \varphi_{2}^{\prime}(U)$, which is equivalent to $\varphi_{2}(U)$ being a concave transformation of $\varphi_{1}(U)$. Throughout the paper, we assume that $\varphi^{\prime \prime}(U)<0$ so that the firm is ambiguity averse.

\section{Optimal production and export decisions}

In this section, we examine the firm's production and export decisions. To have a nontrivial problem, we assume hereafter that the expected marginal revenue from selling abroad is greater than that from selling domestically:

$$
\mathrm{E}_{G}\left[\mathrm{E}_{F}(\tilde{S} \mid \tilde{\theta})\right] P_{f}=\mathrm{E}_{F^{\circ}}(\tilde{S}) P_{f}>P_{d}
$$

where $\mathrm{E}_{F^{\circ}}(\cdot)$ is the expectation operator with respect to the objective $\mathrm{CDF}, F^{\circ}(S)$, and the equality follows from Eq. (2). Condition (6) ensures that the firm optimally sells its output in both the home and foreign countries.

Given that condition (6) holds, the first-order conditions for program (3) are given by

$$
\mathrm{E}_{G}\left\{\varphi^{\prime}\left\{\mathrm{E}_{F}\left[U\left(\tilde{\Pi}^{*}\right) \mid \tilde{\theta}\right]\right\} \mathrm{E}_{F}\left\{U^{\prime}\left(\tilde{\Pi}^{*}\right)\left[P_{d}-C^{\prime}\left(Q^{*}\right)\right] \mid \tilde{\theta}\right\}\right\}=0
$$

and

$$
\mathrm{E}_{G}\left\{\varphi^{\prime}\left\{\mathrm{E}_{F}\left[U\left(\tilde{\Pi}^{*}\right) \mid \tilde{\theta}\right]\right\} \mathrm{E}_{F}\left\{U^{\prime}\left(\tilde{\Pi}^{*}\right)\left[\tilde{S} P_{f}-C^{\prime}\left(Q^{*}\right)\right] \mid \tilde{\theta}\right\}\right\}=0
$$

where an asterisk $\left(^{*}\right)$ indicates an optimal level and $Q^{*}=Q_{d}^{*}+Q_{f}^{*}$. The second-order conditions for program (3) are satisfied given the assumed properties of $\varphi(U), u(\Pi)$, and $C(Q)$. Since $\varphi^{\prime}(U)>0$ and $U^{\prime}(\Pi)>0$, Eq. (7) implies that $C^{\prime}\left(Q^{*}\right)=P_{d}$. Hence, the firm's optimal output level, $Q^{*}$, depends neither on the firm's attitude towards ambiguity nor on the ambiguous exchange rate risk. 
To examine the effect of ambiguity on the firm's optimal production and export decisions, we consider a benchmark case wherein there is no ambiguity in that the firm knows the objective CDF of $\tilde{S}$, i.e., $F(S \mid \theta)=F^{\circ}(S)$ for all $S \in[\underline{S}, \bar{S}]$ and $\theta \in[\underline{\theta}, \bar{\theta}]$. In this benchmark case, Eq. (7) and (8) reduce to

$$
\mathrm{E}_{F \circ}\left\{U^{\prime}\left(\tilde{\Pi}^{\circ}\right)\left[P_{d}-C^{\prime}\left(Q^{\circ}\right)\right]\right\}=0
$$

and

$$
\mathrm{E}_{F^{\circ}}\left\{U^{\prime}\left(\tilde{\Pi}^{\circ}\right)\left[\tilde{S} P_{f}-C^{\prime}\left(Q^{\circ}\right)\right]\right\}=0,
$$

where a nought $\left(^{\circ}\right)$ indicates an optimal level in the absence of ambiguity and $Q^{\circ}=Q_{d}^{\circ}+Q_{f}^{\circ}$. We state and prove our first proposition.

Proposition 1. Introducing ambiguity to the ambiguity-averse exporting firm has no effect on the firm's optimal output level, i.e., $Q^{*}=Q^{\circ}$. The firm optimally raises its domestic sales and reduces its foreign exports, i.e., $Q_{d}^{*}>Q_{d}^{\circ}$ and $Q_{f}^{*}<Q_{f}^{\circ}$, if, and only if, the covariance between $\varphi^{\prime}\left\{\mathrm{E}_{F}\left[U\left(\tilde{\Pi}^{\circ}\right) \mid \tilde{\theta}\right]\right\}$ and $\mathrm{E}_{F}\left\{U^{\prime}\left(\tilde{\Pi}^{\circ}\right)\left[\tilde{S} P_{f}-C^{\prime}\left(Q^{\circ}\right)\right] \mid \tilde{\theta}\right\}$ is negative.

Proof. Since $U^{\prime}(\Pi)>0$, Eq. (9) implies that $C^{\prime}\left(Q^{\circ}\right)=P_{d}$. Hence, we have $Q^{*}=Q^{\circ}$. Substituting $Q_{d}=Q^{\circ}-Q_{f}$ into the objective function of program (3), we differentiate the objective function with respect to $Q_{f}$ and evaluate the resulting derivative at $Q_{f}=Q_{f}^{\circ}$ to yield

$$
\begin{aligned}
& \mathrm{E}_{G}\left\{\varphi^{\prime}\left\{\mathrm{E}_{F}\left[U\left(\tilde{\Pi}^{\circ}\right) \mid \tilde{\theta}\right]\right\} \mathrm{E}_{F}\left\{U^{\prime}\left(\tilde{\Pi}^{\circ}\right)\left[\tilde{S} P_{f}-C^{\prime}\left(Q^{\circ}\right)\right] \mid \tilde{\theta}\right\}\right\} \\
& =\mathrm{E}_{G}\left\{\varphi^{\prime}\left\{\mathrm{E}_{F}\left[U\left(\tilde{\Pi}^{\circ}\right) \mid \tilde{\theta}\right]\right\}\right\} \mathrm{E}_{F^{\circ}}\left\{U^{\prime}\left(\tilde{\Pi}^{\circ}\right)\left[\tilde{S} P_{f}-C^{\prime}\left(Q^{\circ}\right)\right]\right\} \\
& \quad+\operatorname{Cov}_{G}\left\{\varphi^{\prime}\left\{\mathrm{E}_{F}\left[U\left(\tilde{\Pi}^{\circ}\right) \mid \tilde{\theta}\right]\right\}, \mathrm{E}_{F}\left\{U^{\prime}\left(\tilde{\Pi}^{\circ}\right)\left[\tilde{S} P_{f}-C^{\prime}\left(Q^{\circ}\right)\right] \mid \tilde{\theta}\right\}\right\} \\
& =\operatorname{Cov}_{G}\left\{\varphi^{\prime}\left\{\mathrm{E}_{F}\left[U\left(\tilde{\Pi}^{\circ}\right) \mid \tilde{\theta}\right]\right\}, \mathrm{E}_{F}\left\{U^{\prime}\left(\tilde{\Pi}^{\circ}\right)\left[\tilde{S} P_{f}-C^{\prime}\left(Q^{\circ}\right)\right] \mid \tilde{\theta}\right\}\right\},
\end{aligned}
$$


where the first equality follows from Eq. (2), the second equality follows from Eq. (10), and $\operatorname{Cov}_{G}(\cdot, \cdot)$ is the covariance operator with respect to the second-order CDF, $G(\theta)$. It then follows from Eq. (8) that $Q_{f}^{*}<Q_{f}^{\circ}$ if, and only if, the covariance term on the right-hand side of Eq. (11) is negative.

Differentiating $\varphi^{\prime}\left\{\mathrm{E}_{F}\left[U\left(\tilde{\Pi}^{\circ}\right) \mid \theta\right]\right\}$ with respect to $\theta$ yields

$$
-\int_{\underline{S}}^{\bar{S}} \varphi^{\prime \prime}\left\{\mathrm{E}_{F}\left[U\left(\tilde{\Pi}^{\circ}\right) \mid \theta\right]\right\} U^{\prime}\left(\Pi^{\circ}\right) P_{f} Q_{f}^{\circ} F_{\theta}(S \mid \theta) \mathrm{d} S,
$$

where $F_{\theta}(S \mid \theta)=\partial F(S \mid \theta) / \partial \theta$, and we have used integration by parts. Likewise, differentiating $\mathrm{E}_{F}\left\{U^{\prime}\left(\tilde{\Pi}^{\circ}\right)\left[\tilde{S} P_{f}-C^{\prime}\left(Q^{\circ}\right)\right] \mid \theta\right\}$ with respect to $\theta$ yields

$$
P_{f} \int_{\underline{S}}^{\bar{S}}\left\{U^{\prime}\left(\Pi^{\circ}\right)\left[R\left(\Pi^{\circ}\right)-1\right]+\left[C^{\prime}\left(Q^{\circ}\right) Q^{\circ}-C\left(Q^{\circ}\right)\right] U^{\prime \prime}\left(\Pi^{\circ}\right)\right\} F_{\theta}(S \mid \theta) \mathrm{d} S,
$$

where $R(\Pi)=-\Pi U^{\prime \prime}(\Pi) / U^{\prime}(\Pi)$ is the firm's coefficient of relative risk aversion, and we have used integration by parts and the fact that $P_{d}=C^{\prime}\left(Q^{\circ}\right)$. Since $C(0)=0$, the strict convexity of $C(Q)$ implies that $C^{\prime}(Q)>C(Q) / Q$ for all $Q>0$. If $R(\Pi) \leq 1$ and $\theta$ ranks $F(S \mid \theta)$ in the sense of first-order stochastic dominance, it follows from Eqs. (12) and (13) that the covariance between $\varphi^{\prime}\left\{\mathrm{E}_{F}\left[U\left(\tilde{\Pi}^{\circ}\right) \mid \tilde{\theta}\right]\right\}$ and $\mathrm{E}_{F}\left\{U^{\prime}\left(\tilde{\Pi}^{\circ}\right)\left[\tilde{S} P_{f}-C^{\prime}\left(Q^{\circ}\right)\right] \mid \tilde{\theta}\right\}$ is indeed negative so that $Q_{d}^{*}>Q_{d}^{\circ}$ and $Q_{f}^{*}<Q_{f}^{\circ}$.

We now examine the effect of greater ambiguity aversion on the firm's optimal production and export decisions when ambiguity prevails. Klibanoff et al. (2005) show that the firm becomes more ambiguity averse when $\varphi(U)$ is replaced by $K[\varphi(U)]$ in the objective function of program $(3)$, where $K(\cdot)$ satisfies that $K^{\prime}(\cdot)>0$ and $K^{\prime \prime}(\cdot)<0$. The more ambiguity-averse firm's ex-ante decision problem is given by

$$
\max _{Q_{d} \geq 0, Q_{f} \geq 0} \mathrm{E}_{G}\left\{K\left\{\varphi\left\{\mathrm{E}_{F}[U(\tilde{\Pi}) \mid \tilde{\theta}]\right\}\right\}\right\}
$$

The first-order conditions for program (14) are given by

$$
\mathrm{E}_{G}\left\{K^{\prime}\left\{\varphi\left\{\mathrm{E}_{F}\left[U\left(\tilde{\Pi}^{\diamond}\right) \mid \tilde{\theta}\right]\right\}\right\} \varphi^{\prime}\left\{\mathrm{E}_{F}\left[U\left(\tilde{\Pi}^{\diamond}\right) \mid \tilde{\theta}\right]\right\} \mathrm{E}_{F}\left\{U^{\prime}\left(\tilde{\Pi}^{\diamond}\right)\left[P_{d}-C^{\prime}\left(Q^{\diamond}\right)\right] \mid \tilde{\theta}\right\}\right\}=0
$$


and

$$
\mathrm{E}_{G}\left\{K^{\prime}\left\{\varphi\left\{\mathrm{E}_{F}\left[U\left(\tilde{\Pi}^{\diamond}\right) \mid \tilde{\theta}\right]\right\}\right\} \varphi^{\prime}\left\{\mathrm{E}_{F}\left[U\left(\tilde{\Pi}^{\diamond}\right) \mid \tilde{\theta}\right]\right\} \mathrm{E}_{F}\left\{U^{\prime}\left(\tilde{\Pi}^{\diamond}\right)\left[\tilde{S} P_{f}-C^{\prime}\left(Q^{\diamond}\right)\right] \mid \tilde{\theta}\right\}\right\}=0
$$

where a diamond $\left({ }^{\diamond}\right)$ indicates an optimal level. We state and prove the following proposition.

Proposition 2. Making the ambiguity-averse exporting firm more ambiguity averse by replacing $\varphi(U)$ by $K[\varphi(U)]$ has no effect on the firm's optimal output level, i.e., $Q^{\diamond}=$ $Q^{*}$. The firm optimally raises its domestic sales and reduces its foreign exports, i.e., $Q_{d}^{\diamond}>Q_{d}^{*}$ and $Q_{f}^{\diamond}<Q_{f}^{*}$, if, and only if, the covariance between $K^{\prime}\left\{\varphi\left\{\mathrm{E}_{F}\left[U\left(\tilde{\Pi}^{*}\right) \mid \tilde{\theta}\right]\right\}\right\}$ and $\varphi^{\prime}\left\{\mathrm{E}_{F}\left[U\left(\tilde{\Pi}^{*}\right) \mid \tilde{\theta}\right]\right\} \mathrm{E}_{F}\left\{U^{\prime}\left(\tilde{\Pi}^{*}\right)\left[\tilde{S} P_{f}-C^{\prime}\left(Q^{*}\right)\right] \mid \tilde{\theta}\right\}$ is negative.

Proof. Since $K^{\prime}(\cdot)>0, \varphi^{\prime}(U)>0$, and $U^{\prime}(\Pi)>0$, Eq. (15) implies that $C^{\prime}\left(Q^{\diamond}\right)=P_{d}$. Hence, we have $Q^{*}=Q^{\diamond}$. Substituting $Q_{d}=Q^{*}-Q_{f}$ into the objective function of program (14), we differentiate the objective function with respect to $Q_{f}$ and evaluate the resulting derivative at $Q_{f}=Q_{f}^{*}$ to yield

$$
\begin{aligned}
& \mathrm{E}_{G}\left\{K^{\prime}\left\{\varphi\left\{\mathrm{E}_{F}\left[U\left(\tilde{\Pi}^{*}\right) \mid \tilde{\theta}\right]\right\}\right\} \varphi^{\prime}\left\{\mathrm{E}_{F}\left[U\left(\tilde{\Pi}^{*}\right) \mid \tilde{\theta}\right]\right\} \mathrm{E}_{F}\left\{U^{\prime}\left(\tilde{\Pi}^{*}\right)\left[\tilde{S} P_{f}-C^{\prime}\left(Q^{*}\right)\right] \mid \tilde{\theta}\right\}\right\} \\
& =\mathrm{E}_{G}\left\{K^{\prime}\left\{\varphi\left\{\mathrm{E}_{F}\left[U\left(\tilde{\Pi}^{*}\right) \mid \tilde{\theta}\right]\right\}\right\}\right\} \mathrm{E}_{G}\left\{\varphi^{\prime}\left\{\mathrm{E}_{F}\left[U\left(\tilde{\Pi}^{*}\right) \mid \tilde{\theta}\right]\right\} \mathrm{E}_{F}\left\{U^{\prime}\left(\tilde{\Pi}^{*}\right)\left[\tilde{S} P_{f}-C^{\prime}\left(Q^{*}\right)\right] \mid \tilde{\theta}\right\}\right\} \\
& +\operatorname{Cov}_{G}\left\{K^{\prime}\left\{\varphi\left\{\mathrm{E}_{F}\left[U\left(\tilde{\Pi}^{*}\right) \mid \tilde{\theta}\right]\right\}\right\}, \varphi^{\prime}\left\{\mathrm{E}_{F}\left[U\left(\tilde{\Pi}^{*}\right) \mid \tilde{\theta}\right]\right\} \mathrm{E}_{F}\left\{U^{\prime}\left(\tilde{\Pi}^{*}\right)\left[\tilde{S} P_{f}-C^{\prime}\left(Q^{*}\right)\right] \mid \tilde{\theta}\right\}\right\} \\
& =\operatorname{Cov}_{G}\left\{K^{\prime}\left\{\varphi\left\{\mathrm{E}_{F}\left[U\left(\tilde{\Pi}^{*}\right) \mid \tilde{\theta}\right]\right\}\right\}, \varphi^{\prime}\left\{\mathrm{E}_{F}\left[U\left(\tilde{\Pi}^{*}\right) \mid \tilde{\theta}\right]\right\} \mathrm{E}_{F}\left\{U^{\prime}\left(\tilde{\Pi}^{*}\right)\left[\tilde{S} P_{f}-C^{\prime}\left(Q^{*}\right)\right] \mid \tilde{\theta}\right\}\right\},(17)
\end{aligned}
$$

where the second equality follows from Eq. (8). It then follows from Eq. (16) that $Q_{f}^{\diamond}<Q_{f}^{*}$ if, and only if, the covariance term on the right-hand side of Eq. (17) is negative.

Suppose that an increase in $\theta$ always deteriorates $F(S \mid \theta)$ in the sense of first-order 
stochastic dominance, i.e., $F_{\theta}(S \mid \theta) \geq 0$ for all $S \in[\underline{S}, \bar{S}]$ and $\theta \in[\underline{\theta}, \bar{\theta}] .{ }^{4}$ Differentiating $K^{\prime}\left\{\varphi\left\{\mathrm{E}_{F}\left[U\left(\tilde{\Pi}^{*}\right) \mid \theta\right]\right\}\right\}$ with respect to $\theta$ yields

$$
-\int_{\underline{S}}^{\bar{S}} K^{\prime \prime}\left\{\varphi\left\{\mathrm{E}_{F}\left[U\left(\tilde{\Pi}^{*}\right) \mid \theta\right]\right\}\right\} \varphi^{\prime}\left\{\mathrm{E}_{F}\left[U\left(\tilde{\Pi}^{*}\right) \mid \theta\right]\right\} U^{\prime}\left(\Pi^{*}\right) P_{f} Q_{f}^{*} F_{\theta}(S \mid \theta) \mathrm{d} S,
$$

where we have used integration by parts. Eq. (18) implies that $K^{\prime}\left\{\varphi\left\{\mathrm{E}_{F}\left[U\left(\tilde{\Pi}^{*}\right) \mid \theta\right]\right\}\right\}$ is increasing in $\theta$. Differentiating $\mathrm{E}_{F}\left\{U^{\prime}\left(\tilde{\Pi}^{*}\right)\left[\tilde{S} P_{f}-C^{\prime}\left(Q^{*}\right)\right] \mid \theta\right\}$ with respect to $\theta$ yields

$$
P_{f} \int_{\underline{S}}^{\bar{S}}\left\{U^{\prime}\left(\Pi^{*}\right)\left[R\left(\Pi^{*}\right)-1\right]+\left[C^{\prime}\left(Q^{*}\right) Q^{*}-C\left(Q^{*}\right)\right] U^{\prime \prime}\left(\Pi^{*}\right)\right\} F_{\theta}(S \mid \theta) \mathrm{d} S,
$$

where we have used integration by parts and the fact that $P_{d}=C^{\prime}\left(Q^{*}\right)$. If $R(\Pi) \leq 1$, Eq. (19) implies that $\mathrm{E}_{F}\left\{U^{\prime}\left(\tilde{\Pi}^{*}\right)\left[\tilde{S} P_{f}-C^{\prime}\left(Q^{*}\right)\right] \mid \theta\right\}$ is decreasing in $\theta$. From Proposition 1, we have $Q_{f}^{*}<Q_{f}^{\circ}$ so that Eq. (10) imply that

$$
\mathrm{E}_{G}\left\{\mathrm{E}_{F}\left\{U^{\prime}\left(\tilde{\Pi}^{*}\right)\left[\tilde{S} P_{f}-C^{\prime}\left(Q^{*}\right)\right] \mid \tilde{\theta}\right\}\right\}>0
$$

Since $\mathrm{E}_{F}\left\{U^{\prime}\left(\tilde{\Pi}^{*}\right)\left[\tilde{S} P_{f}-C^{\prime}\left(Q^{*}\right)\right] \mid \theta\right\}$ is decreasing in $\theta$, Eq. (20) implies that there exists a unique point, $\theta_{1} \in(\underline{\theta}, \bar{\theta})$ such that $\mathrm{E}_{F}\left\{U^{\prime}\left(\tilde{\Pi}^{*}\right)\left[\tilde{S} P_{f}-C^{\prime}\left(Q^{*}\right)\right] \mid \theta\right\}>(<) 0$ for all $\theta<(>) \theta_{1}$. Using Eq. (8), we can write the left-hand side of Eq. (17) as

$$
\begin{aligned}
\mathrm{E}_{G}\left\{\left\{K^{\prime}\left\{\varphi\left\{\mathrm{E}_{F}\left[U\left(\tilde{\Pi}^{*}\right) \mid \tilde{\theta}\right]\right\}\right\}-K^{\prime}\left\{\varphi\left\{\mathrm{E}_{F}\left[U\left(\tilde{\Pi}^{*}\right) \mid \theta_{1}\right]\right\}\right\}\right\}\right. \\
\left.\times \varphi^{\prime}\left\{\mathrm{E}_{F}\left[U\left(\tilde{\Pi}^{*}\right) \mid \tilde{\theta}\right]\right\} \mathrm{E}_{F}\left\{U^{\prime}\left(\tilde{\Pi}^{*}\right)\left[\tilde{S} P_{f}-C^{\prime}\left(Q^{*}\right)\right] \mid \tilde{\theta}\right\}\right\} .
\end{aligned}
$$

Since $K^{\prime}\left\{\varphi\left\{\mathrm{E}_{F}\left[U\left(\tilde{\Pi}^{*}\right) \mid \theta\right]\right\}\right\}$ is increasing in $\theta$, the right-hand side of Eq. (21) must be negative. It then follows from Eq. (17) that the covariance between $K^{\prime}\left\{\varphi\left\{\mathrm{E}_{F}\left[U\left(\tilde{\Pi}^{*}\right) \mid \tilde{\theta}\right]\right\}\right\}$ and $\varphi^{\prime}\left\{\mathrm{E}_{F}\left[U\left(\tilde{\Pi}^{*}\right) \mid \tilde{\theta}\right]\right\} \mathrm{E}_{F}\left\{U^{\prime}\left(\tilde{\Pi}^{*}\right)\left[\tilde{S} P_{f}-C^{\prime}\left(Q^{*}\right)\right] \mid \tilde{\theta}\right\}$ is indeed negative so that $Q_{d}^{\diamond}>Q_{d}^{*}$ and $Q_{f}^{\diamond}<Q_{f}^{*}$.

Before leaving this section, it is worth pointing out the difference between the impact of risk aversion and that of ambiguity aversion. If the firm is purely risk averse, it is

\footnotetext{
${ }^{4}$ The case wherein an increase in $\theta$ always improves $F(S \mid \theta)$ in the sense of first-order stochastic dominance gives the same result.
} 
well-known that introducing exchange rate risk or greater risk aversion always induces the risk-averse firm to sell more in the home country and export less to the foreign country. However, these results hold under ambiguity aversion if, and only if, the necessary and sufficient conditions stated in Propositions 1 and 2 are satisfied. As shown above, if the firm's coefficient of relative risk aversion, $R(\Pi)=-\Pi U^{\prime \prime}(\Pi) / U^{\prime}(\Pi)$, far exceeds unity, the necessary and sufficient conditions stated in Propositions 1 and 2 would be violated. In this case, introducing ambiguity or greater ambiguity aversion would then induce the ambiguityaverse firm to sell less in the home country and export more to the foreign country.

\section{The value to export}

In this section, we examine the firm's incentive to export to the foreign country. When ambiguity prevails, the firm's optimal domestic sales and foreign exports are $Q_{d}^{*}$ and $Q_{f}^{*}$, respectively. We define the certainty equivalent, $C E^{*}$, as the solution to the following equation:

$$
\varphi\left[U\left(C E^{*}\right)\right]=\mathrm{E}_{G}\left\{\varphi\left\{\mathrm{E}_{F}\left[U\left(\tilde{\Pi}^{*}\right) \mid \tilde{\theta}\right]\right\}\right\}
$$

When there is no ambiguity, the firm's optimal domestic sales and foreign exports are $Q_{d}^{\circ}$ and $Q_{f}^{\circ}$, respectively. In this case, we define the certainty equivalent, $C E^{\circ}$, as the solution to the following equation:

$$
\varphi\left[U\left(C E^{\circ}\right)\right]=\varphi\left\{\mathrm{E}_{F^{\circ}}\left[U\left(\tilde{\Pi}^{\circ}\right)\right]\right\}
$$

Comparing $C E^{*}$ and $C E^{\circ}$ yields the following proposition.

Proposition 3. Introducing ambiguity to the ambiguity-averse exporting firm reduces the certainty equivalent, thereby reducing the value to export to the foreign country. 
Proof. Since $\varphi^{\prime \prime}(U)<0$, Jensen's inequality implies that

$$
\mathrm{E}_{G}\left\{\varphi\left\{\mathrm{E}_{F}\left[U\left(\tilde{\Pi}^{*}\right) \mid \tilde{\theta}\right]\right\}\right\}<\varphi\left\{\mathrm{E}_{G}\left\{\mathrm{E}_{F}\left[U\left(\tilde{\Pi}^{*}\right) \mid \tilde{\theta}\right]\right\}\right\}=\varphi\left\{\mathrm{E}_{F^{\circ}}\left[U\left(\tilde{\Pi}^{*}\right)\right]\right\}
$$

where the equality follows from Eq. (2). Since $Q_{d}^{\circ}$ and $Q_{f}^{\circ}$ are the firm's optimal domestic sales and foreign exports, respectively, in the absence of ambiguity, it must be true that

$$
\varphi\left\{\mathrm{E}_{F^{\circ}}\left[U\left(\tilde{\Pi}^{\circ}\right)\right]\right\}>\varphi\left\{\mathrm{E}_{F^{\circ}}\left[U\left(\tilde{\Pi}^{*}\right)\right]\right\} .
$$

Eqs. (24) and (25) imply that

$$
\mathrm{E}_{G}\left\{\varphi\left\{\mathrm{E}_{F}\left[U\left(\tilde{\Pi}^{*}\right) \mid \tilde{\theta}\right]\right\}\right\}<\varphi\left\{\mathrm{E}_{F^{\circ}}\left[U\left(\tilde{\Pi}^{\circ}\right)\right]\right\}
$$

It then follows from Eqs. (22), (23), and (26) that $C E^{*}<C E^{\circ}$.

The intuition for Proposition 3 is as follows. Exporting to the foreign country exposes the firm to the exchange rate risk. The presence of ambiguity creates additional risk to the ambiguity-averse exporting firm. Hence, the firm finds it less attractive to export to the foreign country in the presence than in the absence of ambiguity, rendering that $C E^{*}<C E^{\circ}$. Ambiguity as such reduces the value to export.

When the firm becomes more ambiguity averse in that $\varphi(U)$ is replaced by $K[\varphi(U)]$, where $K(\cdot)$ satisfies that $K^{\prime}(\cdot)>0$ and $K^{\prime \prime}(\cdot)<0$, the firm's optimal domestic sales and foreign exports are $Q_{d}^{\diamond}$ and $Q_{f}^{\diamond}$, respectively. In this case, we define the certainty equivalent, $C E^{\diamond}$, as the solution to the following equation:

$$
K\left\{\varphi\left[U\left(C E^{\diamond}\right)\right]\right\}=\mathrm{E}_{G}\left\{K\left\{\varphi\left\{\mathrm{E}_{F}\left[U\left(\tilde{\Pi}^{\diamond}\right) \mid \tilde{\theta}\right]\right\}\right\}\right\}
$$

Comparing $C E^{*}$ and $C E^{\diamond}$ yields the following proposition.

Proposition 4. Making the ambiguity-averse exporting firm more ambiguity averse reduces the certainty equivalent, thereby reducing the value to export to the foreign country. 
Proof. Since $K^{\prime \prime}(\cdot)<0$, Jensen's inequality implies that

$$
\mathrm{E}_{G}\left\{K\left\{\varphi\left\{\mathrm{E}_{F}\left[U\left(\tilde{\Pi}^{\diamond}\right) \mid \tilde{\theta}\right]\right\}\right\}\right\}<K\left\{\mathrm{E}_{G}\left\{\varphi\left\{\mathrm{E}_{F}\left[U\left(\tilde{\Pi}^{\diamond}\right) \mid \tilde{\theta}\right]\right\}\right\}\right\}
$$

Since $Q_{d}^{*}$ and $Q_{f}^{*}$ are the optimal domestic sales and foreign sales, respectively, when the firm's smooth ambiguity preferences are represented by $\varphi(U)$, it must be true that

$$
\mathrm{E}_{G}\left\{\varphi\left\{\mathrm{E}_{F}\left[U\left(\tilde{\Pi}^{*}\right) \mid \tilde{\theta}\right]\right\}\right\}>\mathrm{E}_{G}\left\{\varphi\left\{\mathrm{E}_{F}\left[U\left(\tilde{\Pi}^{\diamond}\right) \mid \tilde{\theta}\right]\right\}\right\}
$$

Eqs. (28) and (29) imply that

$$
\mathrm{E}_{G}\left\{K\left\{\varphi\left\{\mathrm{E}_{F}\left[U\left(\tilde{\Pi}^{\diamond}\right) \mid \tilde{\theta}\right]\right\}\right\}\right\}<K\left\{\mathrm{E}_{G}\left\{\varphi\left\{\mathrm{E}_{F}\left[U\left(\tilde{\Pi}^{*}\right) \mid \tilde{\theta}\right]\right\}\right\}\right\}
$$

It then follows from Eqs. (22), (27), and (30) that $C E^{\diamond}<C E^{*}$.

The intuition for Proposition 4 is as follows. When the firm is more ambiguity averse, exporting to the foreign country becomes less attractive as the firm has to be exposed to the exchange rate risk. Hence, the certainty equivalent decreases in a systematic manner with greater ambiguity aversion.

\section{Conclusion}

In this paper, we have examined the production and export decisions of an exporting firm that sells in both the home country and a foreign country. The firm's preferences exhibit smooth ambiguity aversion developed by Klibanoff et al. (2005). The KMM model represents ambiguity by a second-order probability distribution that captures the firm's uncertainty about which of the subjective beliefs govern the exchange rate risk. On the other hand, the KMM model specifies ambiguity preferences by the (second-order) expectation

of a concave transformation of the (first-order) expected utility of profit conditional on each plausible subjective distribution of the exchange rate risk. Within this framework, we 
have derived necessary and sufficient conditions under which the ambiguity-averse exporting firm optimally sells more in the home country and exports less to the foreign country in response either to the introduction of ambiguity or to greater ambiguity aversion when ambiguity prevails. We have further shown that the firm finds it less attractive to export to the foreign country in the presence than in the absence of ambiguity, and with greater ambiguity aversion. Ambiguity and ambiguity aversion as such have adverse effect on the firm's incentive to export to the foreign country.

While we have focused on the exporting firm's incentive to trade under ambiguity aversion, we deliberately exclude the possibility that the ambiguity exchange rate risk is hedgeable. It goes without saying that currency hedging is likely to reduce the exchange rate risk, thereby enhancing the value to export. As long as perfect hedging is not implementable, our qualitative results should remain intact. Another interesting extension is to expose the exporting firm to other sources of uncertainty such as political risk, business risk, and price risk. Indeed, not much has been done for the decision making under multiple sources of ambiguity. We leave these challenges for future research.

\section{References}

Alary, D., Gollier, C., Treich, N., 2013. The effect of ambiguity aversion on insurance and self-production. Economic Journal 123, 1188-1202.

Barham, B. L., Chavas, J.-P., Fitz, D., Salas, V. R., Schechter, L., 2014. The role of risk and ambiguity in technology adoption. Journal of Economic Behavior and Organization 97, $204-218$.

Broll, U., Zilcha, I., 1992. Exchange rate uncertainty, futures markets and the multinational firm. European Economic Review 36, 815-826.

Cardenas, J. C., Carpenter, J., 2008. Behavioural development economics: Lessons from 
field labs in the developing world. Journal of Development Studies 44, 311-338.

Chesson, H. W., Viscusi, W. K., 2003. Commonalities in time and ambiguity aversion for long-term risks. Journal of Risk and Uncertainty 24, 57-71.

Chow, C. C., Sarin, R. K., 2001. Comparative ignorance and the Ellsberg Paradox. Journal of Risk and Uncertainty 22, 129-139.

Einhorn, H. J., Hogarth, R. M., 1986. Decision making under ambiguity. Journal of Business $59,225-250$.

Ellsberg, D., 1961. Risk, ambiguity, and the Savage axioms. Quarterly Journal of Economics $75,643-669$.

Engel, C., Rogers, J. H., 1996. How wide is the border? American Economic Review 86, $1112-1125$.

Engel, C., Rogers, J. H., 2001. Violating the law of one price: Should we make a Federal case out of it? Journal of Money, Credit and Banking 33, 1-15.

Gilboa, I., Schmeidler, D., 1989. Maxmin expected utility with non-unique prior. Journal of Mathematical Economics 18, 141-153.

Gollier, C., 2011. Portfolio choices and asset prices: the comparative statics of ambiguity aversion. Review of Economic Studies 78, 1329-1344.

Katz, E., Paroush, J., 1979. The effect of forward markets on exporting firms. Economics Letters $4,272-274$.

Kawai, M., Zilcha, I., 1986. International trade with forward-futures markets under exchange rate and price uncertainty. Journal of International Economics 20, 83-98.

Klibanoff, P., Marinacci, M., Mukerji, S., 2005. A smooth model of decision making under ambiguity. Econometrica 73, 1849-1892.

Knight, F. H., 1921. Risk, Uncertainty and Profit. Boston: Houghton Mifflin.

Parsley, D. C., Wei, S. J., 1996. Convergence to the law of one price without trade barriers 
or currency fluctuations. Quarterly Journal of Economics 111, 1211-1236.

Pratt, J. W., 1964. Risk aversion in the small and in the large. Econometrica 32, 122-136.

Roberts, M., Tybout, J., 1997. An empirical model of sunk costs and the decision to export. American Economic Review 87, 545-564.

Sarin, R. K., Weber, M., 1993. Effects of ambiguity in market experiments. Management Science 39, 602-615.

Snow, A., 2010. Ambiguity and the value of information. Journal of Risk and Uncertainty 40, 133-145.

Snow, A., 2011. Ambiguity aversion and the propensities for self-insurance and self-protection. Journal of Risk and Uncertainty 42, 27-43.

Taboga, M., 2005. Portfolio selection with two-stage preferences. Finance Research Letters $2,152-164$.

Viaene, J.-M., Zilcha, I., 1998. The behavior of competitive exporting firms under multiple uncertainty. International Economic Review 39, 591-609.

Viscusi, W. K., Chesson, H. W., 1999. Hopes and fears: the conflicting effects of risk ambiguity. Theory and Decision 47, 153-178.

Wong, K. P., 2007. Optimal export and hedging decisions when forward markets are incomplete. Bulletin of Economic Research 59, 67-81.

Wong, K. P., 2015. Ambiguity and the value of hedging. Journal of Futures Markets 35, $839-848$.

Wong, K. P., 2016. A smooth ambiguity model of the competitive firm. Bulletin of Economic Research 68, in press. 